\title{
Superior semicircular canal dehiscence syndrome as diagnosis of vestibular pathology; diagnosis and treatment: review of the literature
}

\begin{abstract}
Introduction: Superior Semicircular Canal Dehiscence Syndrome is a pathological entity that causes incapacitating auditory and vestibular symptoms. It is common that these patients are erroneously diagnosed with simulators or psychiatric diseases, or with any other vestibular pathologies.
\end{abstract}

Etiology: It seems to have a genetic predisposition supported in a higher frequency of Semicircular Canal Dehiscence and bone defects in the tegmen tympani in patients with DFNA 9 (gen $\mathrm{COCH}$ ). In other cases there is no specific cause justifying communication between the SSC and cranial cavity. Over the years, and the progressive thinning of the bone, the communication between membranous labyrinthine and cranial cavity, will occur.

Pathophysiology: Superior Semicircular Canal Dehiscence Syndrome is characterized by thinning or loss of bone that covers the SSC and which separates it from of the cranial cavity. A pathologic third window on the vestibular side of the cochlea allows for a portion of acoustic energy to be shunted away from the cochlear partition, producing a decrease in the sound pressure within the vestibule, thus resulting in a loss of hearing sensitivity to airconducted sound (conductive hearing loss) and increases the pressure difference between the two sides of the cochlear partition by lowering the impedance on the vestibule side, thereby improving the cochlear response to bone conduction (supraliminal levels).

Diagnosis: Is based on the clinical history (auto phony, fluctuating hearing loss, acute or short-term vertigo). Typically patients complain of auto phony and feeling of being "in a box". The audio vestibular tests will confirm the clinical diagnosis: PTTA with GAP in low frequencies, VEMPs with threshold elevation in affected ear and CT with SSC dehiscence.

Treatment: The initial treatment of this pathology should be conservative. If the symptoms are disabling it may raise a surgical solution that is the closure of the communication between the SSC and the floor of the middle fossa. The different types of surgical treatment are: access to the middle cranial fossa by temporal craniotomy; access to the SSC by upper Tran's mastoid access, and finally, strengthening of the oval and round windows membranes by endaural access.

Case Report: Present four patients diagnosed and treated surgically in our hospital. Comment their post operatory evolution and the functional results.

Conclusion: The SCD is a pathologic entity that must be present in the differential diagnosis of all patients with audio logical and vestibular symptoms. Their initial treatment should be conservative, but if the symptoms are disabling, surgery should be recommended since results are very good, compensating risks.

Keywords: superior semicircular, canal dehiscence syndrome, vestibular pathology, vertigo, auto phony, tullio phenomenon, surgery treatment
Volume 6 Issue 3 - 2017

Valdés-Pons R,' Palomino Oquendo JC, ${ }^{2}$ Eiroa Breijo A,' Pazo Irazu S,' Martínez Egido I,' Santamaría Castro ML,' González Prado A' $^{\prime}$

'Department of Head and Neck Surgery Otolaryngology Hospital Povisa, Spain

2Department of Neurosurgery, Spain

Correspondence: Valdés-Pons R, Head of Department of Otolaryngology, Head and Neck Surgery, Hospital Povisa,Vigo, Spain,Email rvaldes@povisa.es

Received: August 28, 2016 | Published: March 17, 2017
Abbreviations: SSC, superior semicircular canal; CT, computed tomography; MCF, middle cerebral fossa; SCD, superior canal dehiscence; $\mathrm{COCH}$, cochlin; DFNA9, deafness autosomal dominant 9; PTTA, pure tone threshold audiometry; VEMPs, vestibular evoked myogenic potentials; VNG, video nystagmo graphy

\section{Introduction}

It has known that sound can activate the vestibular system. ${ }^{1}$ In studies conducted at the beginning of the twentieth century by Tullio ${ }^{2}$ and subsequently by Huizinga ${ }^{3}$ it was noted that the fenestration of the semicircular canals in pigeons, caused cephalic and eye movements in the same plane that the damaged canal. They also noted that this same happened by subjecting the ear to intense sounds (Tullio phenomenon).
The same results were obtained when exerting pressure on the ear canal in certain otological diseases that produce a fenestration of the bony labyrinth (sign of Hennebert). ${ }^{4}$ These vestibular alterations appears in various pathologies of the inner ear (perilymphatic fistula, congenital deafness, Meniere's disease, Lyme disease, traumatic brain injury and cholesteatoma). In these cases it was thought that the mechanism responsible for the symptoms would be the existence of a pathological "third window" in the inner ear. At the end of the 1980 s, Minor $^{5}$ described in 8 patients, a new entity that could not be explained by any other known pathological picture. Patients complain of vertigo, oscilopsia, imbalance related to exposure to noise or changes in middle ear pressure and otoneurological signs that only they were explained by an alteration of the superior semicircular cannel (SSC) of the affected ear. Minor found in the temporal bone CT 
of all patients, a dehiscence of the most cranial part of the SSC of the affected ear. This syndrome was called Superior Semicircular Canal Dehiscence (SSCD) and concluded that I was produced when there is a continuity solution between the top of the SSC and the Middle Cerebral Fossa (MCF).

Etiology: In the first study conducted by Minor, none of the patients studied had a history of previous otological disease or other disease that could explain symptoms and signs. Carey et.al published in $2007^{6}$ a study in which analyzed 1,000 temporal bones of 596 adults. The studies identified dehiscence $(0.7 \%)$ or at least thinning $(1.3 \%)$ of SSC in $2 \%$ of individuals studied, sites committed most frequently were the petrosal sinus and the highest point of the SSC. Local alterations ${ }^{7}$ that could explain the bone erosion were not found and none of the patients studied had previous history of cranial trauma. Also observed that the slimming or dehiscence was bilateral (Figure 1) in most of the patients, so authors concluded that any alteration in early stages of the development of the individual could explain these finds and that, probably, some event back, as a trauma or increase of the pressure intracranial, could emphasize this condition and determine the appearance of those symptoms, as they usually appears in the middle ages of life, Therefore, radiological alterations should be congenital. In another study performed by Williamson et al., ${ }^{8}$ the SSCD prevalence of $9 \%$ in CT studies was noted, finding a bilateral commitment in nine of the thirty cases diagnosed as SSCD. Average age of those studied patients was of 45 years, with a distribution equivalent by sex. However, only a small percentage of the patients studied had symptoms compatible with SSCD. Hildebrand et al., ${ }^{9}$ published a possible association between the SSCD and mutations in the $\mathrm{COCH}$ gene that is responsible for the no syndromic dominant autosomal hearing loss DFNA9. Recently, Noonan et al., ${ }^{10}$ found in children with a CDH23 (Usher syndrome or non-syndromic deafness) that they have a significantly increased risk of having SCD and this may be a contributing factor to the vestibular dysfunction in Usher syndrome type 1D patient population.

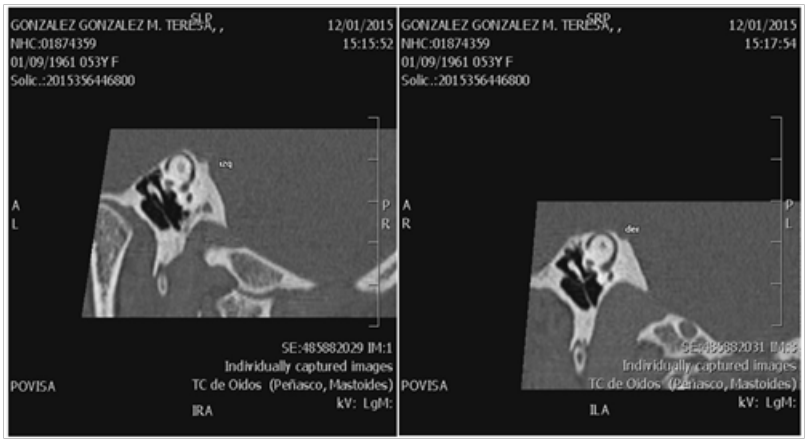

Figure I Bilateral dehiscence of the superior semicircular canal.

Pathophysiology: Superior Semicircular Canal Dehiscence Syndrome is characterized by thinning or loss of bone that covers the SSC and which separates it from the intracranial cavity, therefore there will be a communication between the vestibule and the endocranium that what will result in a pathological third window on the inner ear. ${ }^{11,12}$

Diagnosis: Is based on the characteristic symptoms of these patients. Physical exploration, neurophysiological test and cranial base, confirm the diagnosis. Clinical history: Superior Semicircular Canal dehiscence usually appears in patients with a clinical history of auto phony, fluctuating hearing loss, acute or short-term vertigo. Typically patients complain of auto phony and feeling of being "in a box". Vertigo can be intermittent, but the oscilopsia is disabling. These patients are usually diagnosed as cervicovestibular syndrome, anxiety, or simulation.

Exploration: After stimulation of the SSC, there is a nystagmus caused by contraction of the ipsilateral superior rectus muscle and contra lateral inferior oblique muscle. This causes a nystagmus whose slow phase has a vertical direction towards up and counterclockwise in the stimulation of the right SSC and vertical towards up and clockwise in the stimulation of the left SSC. In the SSC dehiscence, exposure to intense noise, positive pressure in the ear canal and/or the realization of the Valsalva maneuver with the stuffy nose (open glottis) lead a deflection (excitatory) ampullifuga of the dome in the CSS. However, the application of a negative pressure in the ear canal, the Valsalva maneuver with closed glottis and compression jugular generates ampullipeta (inhibitory) deflection in the dome in the CSS. ${ }^{13}$

Testing: Tympanometry and stape dial reflexes are normal with normal ear drum. Pure tone threshold audio metry (PPTA) presents a transmission hearing loss with GAP in the low and middle frequencies and supraliminal levels in the highest frequencies. The spontaneous otoacoustic emissions may be present. Vestibular Evoked Myogenic Potentials (VEMPs) usually have a higher threshold in the affected ear, ${ }^{14}$ but if hearing loss is bigger than $30-40 \%$, the VEMPs will not appear. The CT study presents a middle ear without injury. CT helps to discard diseases of the middle ear that can simulate this syndrome and discarded the possibility of otosclerosis or tympanoesclerosis. Otherwise, there will be a bone dehiscence in the dome of the superior semicircular canal (Figure 2). The positive predictive value of the CT in the diagnosis of the dehiscence increases by making cuts of $0.5 \mathrm{~mm}$ and reconstructing in the flat of the SSC. ${ }^{12}$

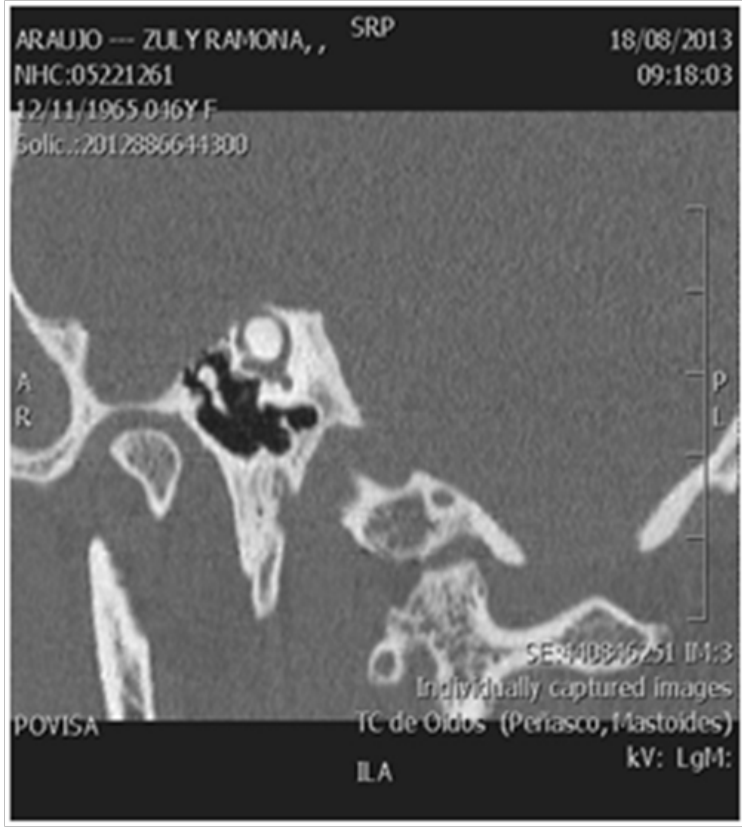

Figure 2 Intact middle and internal ear structures except the right CSS dehiscence.

Treatment: The initial treatment of this pathology should be conservative. If the symptoms are disabling it may raise a surgical solution which is the closure of the communication between the SSC and the floor of the middle fossa. There are several approximations for the closure of the fistula:

A. By middle cerebral fossa through a parietotemporal craniotomy; ${ }^{15}$ 
B. The same approach but using endoscopesso the aggressiveness of the intervention is reduced (minimally invasive surgery);

C. Superior Transmastoidea approach; ${ }^{16-18}$

D. Strengthening of the round and oval windows membranes by endaural approach, ${ }^{19,20}$ although the results of this technique should be confirmed; and finally,

E. Combining the approximation by middle cerebral fossa and the strengthening of the oval and round window by endaural approach. ${ }^{21}$

The dehiscence it can be sealed with bone wax or a bone graft, or adding temporal muscle fascia or the own muscle. ${ }^{22,23}$ The major surgical treatments involve a number of risks inherent in the type of surgery, but in addition to these risks and sequel, access by the middle cerebral fossa could cause sensor neural hearing loss in patients who have to be revised in the future or have been surgically treated previously by stapedotomy. ${ }^{24}$ In addition, Transmastoidea and endaural approach can produce vestibularhypo function in addition of sensor neural hearing loss. ${ }^{25}$ It is considered that around $25 \%$ of patients surgically treated; return to have symptoms after some years, although of lesser intensity. For all these reasons the current trend is to intervene surgically only in those cases with severe or debilitating symptoms or using minimally invasive techniques. ${ }^{26}$

Table I Patients with a Diagnosis of scd Syndrome

\begin{tabular}{|c|c|c|c|c|}
\hline & Case I & Case 2 & Case 3 & Case 4 \\
\hline Age & 50 & 54 & 64 & 58 \\
\hline Gender & $\mathrm{F}$ & $\mathrm{F}$ & M & $\mathrm{F}$ \\
\hline Time evolution & 35 months & 15 years & $>10$ years & $<12$ years \\
\hline Autophony & Yes & Yes & Yes & Yes \\
\hline Hearing loss & No & Yes & Yes & Yes \\
\hline Tinnitus & Fluctuating, Right ear & $\begin{array}{l}\text { Fluctuating, } \\
\text { Bilateral }\end{array}$ & Yes & Left ear \\
\hline Vertigo & YES Positive phenomenon Tullio & Yes & Yes & Yes \\
\hline Oscilopsia & No & Yes & Yes & Yes \\
\hline VNG & No & Normal & Right hyporreflexia & Right hyporreflexia \\
\hline \multirow[t]{2}{*}{ VEMPs } & Right ear threshold elevation & Normal & Right ear threshold & Bilateral threshold \\
\hline & & & elevation & elevation \\
\hline PTTA & GAP $20 \mathrm{~dB}$ & $\begin{array}{l}\text { SNHL left ear } \\
(50 \mathrm{~dB})\end{array}$ & $\begin{array}{l}\text { Progressive SNHL right } \\
\text { ear, }\end{array}$ & $\begin{array}{l}\text { Bilateral GAP } 30 \mathrm{~dB} \text { in low } \\
\text { frequencies }\end{array}$ \\
\hline TAC pre & Right SCD. & Bilateral SCD & $\begin{array}{l}\text { Right SCD, intense } \\
\text { slimming of left SSC }\end{array}$ & Bilateral SCD. \\
\hline Surgery and Date & $\begin{array}{l}\text { Right middle cerebral fossa through } \\
\text { a parietotemporal craniotomy. } \\
\text { (I I/28/20I3) }\end{array}$ & $\begin{array}{l}\text { Left middle } \\
\text { cerebral fossa } \\
\text { through a } \\
\text { parietotemporal } \\
\text { craniotomy. } \\
(01 / 19 / 2015)\end{array}$ & $\begin{array}{l}\text { Right middle cerebral } \\
\text { fossa through a } \\
\text { parietotemporal } \\
\text { craniotomy. }(01 / 26 / 2015)\end{array}$ & $\begin{array}{l}\text { Right middle cerebral fossa throug } \\
\text { a parietotemporal craniotomy. } \\
\text { (12/14/20I5) }\end{array}$ \\
\hline $\begin{array}{l}\text { Complications } \\
\text { Postsurgical }\end{array}$ & No & No & No & No \\
\hline Symptoms Post Surgery & No & Instability & Instability & Instability \\
\hline PTTA Post Surgery & Unchanged & Unchanged & Unchanged & Unchanged \\
\hline $\begin{array}{l}\text { Time of Evolution from } \\
\text { Surgery }\end{array}$ & 34 months & 21 months & 20 months & 9 months, pending left surgery \\
\hline
\end{tabular}

VNG:Video Nystagmo Graphy; SNHL: Sensori Neural Hearing Loss; SCD: Superior Canal Dehiscence; MCF: Middle Cerebral Fossa. PTTA: Pure Tone Threshold Audiometry; GAP:Air-Bone Difference

\section{Cases report}

Present four cases diagnosed and treated in the last three years. As it can be seen in Table 1, all of them had long evolution vestibular symptoms with previous diagnostic error of vascular or viral vestibulopaty, ototubaritis, middle ear pathology (tympanoesclerosis), unspecific vertigo and, frequently, anxiety. The third case was treated with antidepressants during 10years. In the second, third and fourth cases, the radiological dehiscence was bilateral. The decision of which SSC obliterate was based on physical examination, location of the audio logical symptoms and the VEMPs. After the failure of pharmacological treatment, the surgically treatment was offered and accepted. There were no postoperative complications and the stay in the critical unit was 24hours. Hospital discharge was carried out at 36 hours. The surgical intervention was carried out in cooperation with the Department of Neurosurgery of our center and for the obliteration of the canal defect, surgical wax and fascia of the temporal muscle was used. The audio vestibular evolution of all of them was satisfactory. In the first three cases, the auto phony, vertigo and feeling of optic plugging disappeared. In the cases with bilateral dehiscence, if symptoms continue after surgical treatment, it is proposed the same treatment for the other ear. This is the situation of the fourth case that is pending of surgical treatment in the left ear. In cases of long evolution, with labyrinthine chronic damage, sensor neural hearing loss and instability persists.

\section{Conclusion}

Since end of the 80s Decade, when Minor et.al described this syndrome until nowadays, there has been many publications that have corroborated the existence of this pathological entity. The SDCSS perfectly describes the audio logical and vestibular symptoms and 
signs presented in a considerable number of patients with vertigo. Until it was not established as pathology of the inner ear, many of them were diagnosed erroneously as simulators, psychiatric patients or patients with unusual vestibular pathology. The objectives tests, VEMP, PTTA and CT along with symptomatology and clinical history, are the only tools to diagnose the SDCSS. The clinical picture is characteristic, so the diagnosis is relatively easy providing the physician note of this type of vestibular disease. The presence of CSS dehiscence in the CT is very common as it has been already noted, but, if is not associated with compatible clinical history is not as its cause. ${ }^{27}$ In the last years this syndrome has been described in patients which only manifested of hearing without vestibular symptoms ${ }^{28,29}$ doing more complicated the diagnosis. The surgical treatment is applied in those patients in which the disease is disabling. In the four cases presented we use the middle temporal fossa approach with SSC location by using neuro navigation and surgical wax for blocking the canal. In all four cases postoperative incidents did not rule out being well tolerated by patients. The postoperative period of our patients was bland, there were no important sequels except headache in one of them. In all the cases the auto phony, acute vertigo and fluctuating tinnitus disappeared. Disabling symptoms persist in those cases where membranous labyrinth was damaged previously and in cases with bilateral dehiscence. ${ }^{30,31}$ The SDCSS is a pathologic entity that must be present in the differential diagnosis of all patients with audio logical and vestibular symptoms. Their initial treatment should be conservative, but if the symptoms are disabling, surgery should be recommended because results are very good, and the results outweigh the potential risks.

\section{Acknowledgments}

Santos-Armentia E, MD, Silvia-Priegue N, Department of Radiology.

\section{Conflicts of interest}

Author Valdés-Pons $\mathrm{R}$ declares that he has no conflict of interest. Author Eiroa-Breijo A declares that she has no conflict of interest. Author Pazo-Irazu S that she has no conflict of interest. AuthorMartínez-Egido I that she has no conflict of interest. The author Santamaría-Castro ML declares that she has no conflict of interest. Author González-Prado A declares that he has no conflict of interest. Author Palomino-Oquendo JC declares that he has no conflict of interest.

\section{Funding}

None.

\section{References}

1. Nadol JB. Positive Hennebert's sign in Méniére's disease. Arch Otolaryngol. 1977;103(9): 524-530.

2. Tullio P. Das Ohr und die Entstehung der Sprache und Schrift. Berlin, Germany: Urban \& Schwarzenberg. 1929.

3. Huizinga E. on the sound reactions of Tullio. Acta Otolaryngol (Stockh). $1935 ; 22: 359-369$

4. Hennebert C. A new syndrome in hereditary syphilis of the labyrinth Presse Med Belg Brux. 1911;63:467.

5. Minor LB, Solomon D, Zinreich JS, et al. Sound and/or pressure-induced vertigo due to bone dehiscence of the superior semicircular canal. Arch Otolaryngol Head Neck Surg. 1998;124(3):249-258.
6. Carey JP, Migliaccio AA, Minor LB. Semicircular canal functions before and after surgery for superior canal dehiscence. Otol Neurotol. 2007;28(3):356-364.

7. Hirvonen TP, Weg N, Zinreich SJ, et al. High-resolution CT Findings Suggest a Development Abnormality Underlying Superior Canal Dehiscence Syndrome. Acta Oto-Laryngological. 2010;123(4):477-481.

8. Williamson RA, Vrabec JT, Coker NJ, et al. Coronal computed tomography prevalence of superior semicircular canal dehiscence. Otolaryngol Head Neck Surg. 2003;129(5):481-489.

9. Hildebrand MS, Tack D, Deluca A, et al. Mutation in the $\mathrm{COCH}$ gene is associated with superior semicircular canal dehiscence. Am J Med Genet A. 2009;149A(2):280-285.

10. Noonan KY, Russo J, Shen J, et al. CDH23 Related Hearing Loss: A New Genetic Risk Factor for Semicircular Canal Dehiscence? Otol Neurotol. 2016;37(10):1583-1588.

11. Merchant SN, Rosowski JJ. Conductive Hearing Loss Caused by ThirdWindow Lesions of the Inner Ear. Otol Neurotol. 2008;29(3):282-289.

12. Minor LB. Clinical Manifestations of Superior Semicircular Canal Dehiscence. Laryngoscope. 2005;115(10):1717-1727.

13. Boleas Aguirre MS, Migliaccio A, Carey J. Characterization of bilateral superior canal dehiscence. Acta Otorrinolaringol Esp. 2007;58(9): 437-439.

14. Streubel SO, Cremer PD, Carey JP, et al. Vestibular-Evoked Myogenic Potentials in the Diagnosis of Superior Canal Dehiscence Syndrome. Acta Oto-Laryngologica. 2009; 121(545):41-49.

15. Chung LK, Ung N, Spasic M, et al. Clinical outcomes of middle fossa craniotomy for superior semicircular canal dehiscence repair. $J$ Neurosurg. 2016;125(5):1187-1183.

16. Brantberg K, Bergenius J, Mendel L, et al. Symptoms, findings and treatment in patients with dehiscence of the superior semicircular canal. Acta Otolaryngol. 2001;121(1):68-75.

17. Babcok TA, Angeki SI, Telischi F, et al. Surgical Outcomes Following Transmastoid Approach for Repair of Superior Semicircular Canal Dehiscence. J Neurol Surg. 2016; 77-A100.

18. Van Haesendonck G, Van de Heyning P, Van Rompaey V. Retrospective cohort study on hearing outcome after Trans mastoid plugging in superior semicircular canal dehiscence syndrome: Our Experience. Clin Otolaryngol. 2015;41(5):601-606.

19. Kartush JK. Superior Canal Dehiscence Syndrome symptoms resolved by reinforcement of the oval and round windows. Unpublished data. 2002.

20. Silverstein H. Round Window Reinforcement for Superior Canal Dehiscence. Oto-HNS. 2012;147:93.

21. Silverstein H, Kartush JM, Parnes LS, et al. Round window reinforcement for superior semicircular canal dehiscence: A retrospective multi-center case series. Am J Otolaryngol . 2014;35(3):286-293.

22. Caro J, Fernández F.Síndrome de dehiscencia Del canal semicircular superior: Revisión. Rev Otorrinolaringol Cir Cabeza Cuello. 2006;66:119-125.

23. O'Connell BP, Hunter JB, Hovis KL, et al. Fascia with bone pate resurfacing technique in repairing superior semicircular canal dehiscence. J Neurol Surg. 2016;77S(1):105.

24. Limb CJ, Carey JP, Srireddy S, et al. auditory function in patients with surgically treated superior semicircular canal dehiscence. Otol Neurotol. 2007;27(7):969-980.

25. Carey JP, Migliaccio AA, Minor LB. Semicircular canal function before \& after surgery for superior canal dehiscence. Otol Neurotol. 2007;28(3):356-364. 
26. Shaia WT, Kartush JM.Superior canal dehiscence. E-medicine Web site. 2007.

27. Williamson RA, Vrabec JT, Coker NJ, et al. Coronal computed tomography prevalence of superior semicircular canal dehiscence. Otolaryngol Head Neck Surg. 2003;129(5):481-489.

28. Teixeira EO, Fonseca MT. Superior Semicircular Canal Dehiscence Syndrome without Vestibular Symptoms. Int Arch Otorhinolaryngol. 2014; 18(2):210-212.
29. Mikulec AA, McKenna MJ, Ramsey M, et al. Superior Semicircular Canal Dehiscence Presenting as Conductive Hearing Loss without Vertigo. Otol Neurotol. 2004; 25(2):121-129.

30. Mantokoudis G, Saber Tehrani AS, et al. Adaptation and Compensation of Vestibular Responses Following Superior Canal Dehiscence Surgery. Otol Neurotol. 2016;37(9):1399-1405.

31. Mehmet G, Mesut K, Selim U, et al. Bilateral superior semicircular canal dehiscence. J Int Adv Otol Suppl. 2015;(11): 80-80. 